\title{
Effects of shock schedules on the acquisition and extinction of escape behavior ${ }^{1,2}$
}

JOSEPH J. FRANCHINA

SOUTHERN METHODIST UNIVERSITY

Three groups of albino rats ( $\mathrm{N}=12 \mathrm{Ss}$ per group) received 72 escape training trials in a hurdle-jumping apparatus, with shock presentation on $33 \%, 66 \%$, or $100 \%$ of the trials, followed by 72 extinction trials. Performance during acquisition was directly related to percentage of shock presentation $(\mathrm{p}<.00 \mathrm{l})$; performance during extinction, in terms of relative scores, demonstrated the PRE $(p<.01)$.

Runway studies by Jones (1953) and Melvin (1963) demonstrated that the resistance to extinction of escape behavior was inversely related to percentage of shock presentation during shock-escape training. Considering the acquisition of escape behavior, however, Jones reported that an intermittent schedule of shock presentation produced faster total running speeds and reliably faster starting speeds than did a continuous schedule of shock presentation; while Melvin reported a direct but non-significant relationship between alley speed and percentage of shock presentation. The present experiment attempted to clarify the relationship between shock schedules and escape behavior by using a different training situation and a greater number of training trials than were used by Jones and Melvin.

Method

Apparatus. The apparatus consisted in a start box and a safe box, each $11-1 / 4$ in. long by $3-1 / 2$ in. wide by $5-1 / 2$ in. high (interior dimensions), separated by a guillotine door on a hurdle $2-1 / 4$ in. high. The start box was painted white and had a grid floor consisting of 30 stainless steel rods, $1 / 8$ in. thick, set $3 / 8$ in. apart. The rods were wired in an alternate-bar system for the delivery of 50 volts (dc) shock to $S$ from a constant voltage source. $S$ provided the only resistance in the shock circuit. The safe box was painted black and had a solid floor which could be depressed.

Additional compartments, each $10-1 / 2$ in. long by $3-1 / 2$ in. wide by 13 in. high (interior dimensions), served as lids for the start box and the safe box. Each lid contained a 7-1/2-watt lamp which provided an intertrial illumination of $7 \mathrm{ft} .-\mathrm{c}$ in each lower box. The lid of the start box also contained a 40-watt lamp for the CS, which was an increase in start box illumination from $7 \mathrm{ft} .-\mathrm{c}$ to $110 \mathrm{ft}$. $-\mathrm{c}$. The illumination was diffused into the lower boxes through frosted Plexiglas $3 / 16$ in. thick.

Subjects, Design and Procedures. Ss were 36 experimentally-naive, female, Holtzman albino rats 99-106 days old. They were randomly assigned to three groups ( $\mathrm{N}=12 \mathrm{Ss}$ ) to receive escape training with shock presentation on $33 \%, 66 \%$ or $100 \%$ of the trials.
Following a day on which $\mathrm{S}$ explored each side of the apparatus for $6 \mathrm{~min}$., each $\mathrm{S}$ received in succession, 2 days of 36 escape training trials per day and then, 2 days of 36 extinction trials per day. The minimal intertrial interval was 45 sec. During escape training, a shock trial consisted in placing $S$ into the start box and, after $10 \mathrm{sec}$, opening the guillotine door, thereby simultanesouly producing the onset of the CS, the shock, and a timer (calibrated in $.01 \mathrm{sec}$.). If $\mathrm{S}$ jumped the hurdle, the safe box floor depressed, terminating the $\mathrm{CS}$ and the timer. After $10 \mathrm{sec}$., Swas removed from the apparatus. If $\mathrm{S}$ failed to jump the hurdle within 40 sec., S was removed from the start box with the $\mathrm{CS}$, the shock, and the timer remaining on and a 40-sec. latency was recorded. Non-shock training trials and extinction trials were conducted exactly like shock training trials, except that no shock was presented. The sequence of shock $(+)$ and non-shock $(-)$ trials, during training was +-+---+++---+--++ for the $33 \%$ group, and +-++-+-++++-++-++ for the $66 \%$ group, repeated over blocks of 18 trials. The measure of performance was reciprocal of latency of hurdle-jumping.

\section{Results}

Figure 1 shows that on each trial block of training, escape performance was directly related to percentage of shock presentation. A trend analysis of variance over all the training data yielded significant effects for

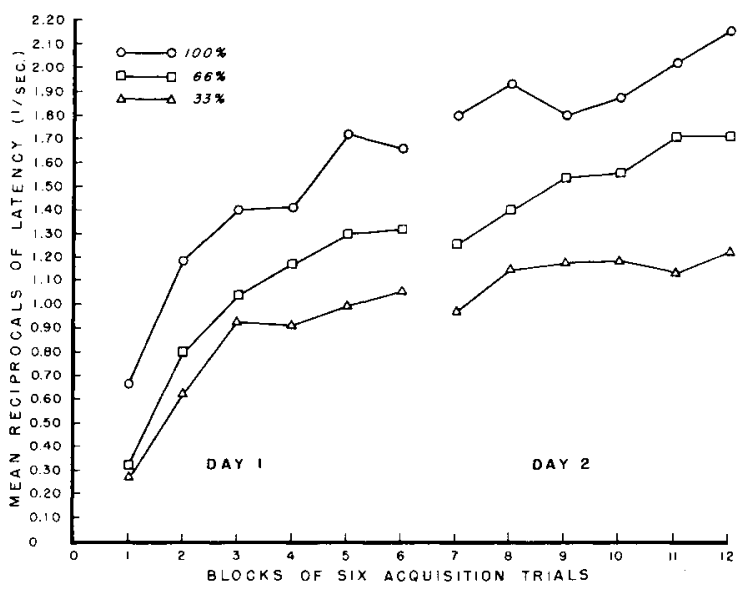

Fig. 1. Mean reciprocals of latency of hurdle-jumping during training for groups that received shock on $33 \%, 66 \%$, or $100 \%$ of the trials. 
Percentage of Shock $(\mathrm{F}=25.71, \mathrm{df}=2 / 33, \mathrm{p}<.001)$ Trial Blocks $(\mathrm{F}=70.21$, $\mathrm{df}=11 / 363, \mathrm{p}<.001)$ and Percentage of Shock by Trial Blocks ( $F=1.82, \mathrm{df}=22 / 363$, $\mathrm{p}<.025)$. To investigate the significant interaction, an analysis of variance and t-tests were applied to the data of Trial Blocks 1 and 12 separately. The analysis of variance showed that Percentage of Shock was significant on Trial Block $1(\mathrm{~F}=10.00, \mathrm{df}=2 / 33, \mathrm{p}<.001)$ and on Trial Block $12(\mathrm{~F}=25.85, \mathrm{df}=2 / 33, \mathrm{p}<.001)$ 。 For Trial Block 1, the results of the t-tests, with $33 \mathrm{df}$, showed that the $100 \%$ group was superior to the $66 \%$ group $(t=7.23, p<.001)$ and to the $33 \%$ group $(t=8.30$, $p<.001$ ) but that the $66 \%$ and the $33 \%$ groups did not differ significantly $(t=1.06, p=.30)$. For Trial Block 12 , the results of the t-tests showed significant differences beyond the .001 level, with $33 \mathrm{df}$, for all percentage group comparisons: $100 \%$ vs. $66 \%, \mathrm{t}=6.88,100 \%$ vs. $33 \%, t=14.53$, and $66 \%$ vs. $33 \%, t=7.66$.

Figure 2 shows that extinction performance, in general, was directly related to performance at the end of acquisition. Since the analysis of the terminal acquisition data indicated that the performances of the percentage groups represented different populations at the start of extinction, extinction performance was evaluated in terms of relative extinction scores (Anderson, 1963). Relative extinction data, called percent difference scores, were obtained for each $\mathrm{S}$ on each trial block of extinction by dividing mean performance on the last trial block of acquisition into the difference in mean performance between the last trial block of acquisition and each trial block of extinction. The percent difference scores showed that on each day of extinction, resistance to extinction was inversely related to percentage of shock during training (i.e. $33 \%>66 \%$ $>100 \%$ ).

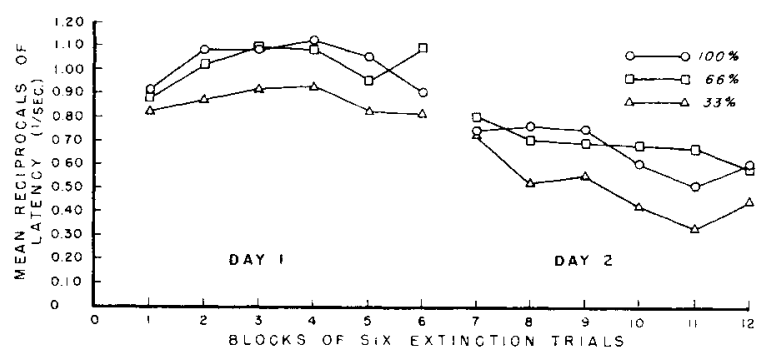

Fig. 2. Mean reciprocals of latency of hurdle-jumping during extinction for groups that received $33 \%, 66 \%$, or $100 \%$ shock during escape training.
Analyses of variance of the overall percent difference data on each day of extinction showed: for Day 1 (Trial Blocks 1-6), Percentage of Shock $(\mathrm{F}=5.82, \mathrm{df}=2 / 33$, $\mathrm{p}<.01)$ Trial Blocks $(\mathrm{F}=2.53, \mathrm{df}=5 / 165, \mathrm{p}<.025)$ for Day 2 (Trial Blocks 7-12), Trial Blocks ( $F=8.93$, $\mathrm{df}=5 / 165, \mathrm{p}<.005)$ Percentage of Shock by Trial Blocks $(\mathrm{F}=2.08, \mathrm{df}=10 / 165, \mathrm{p}<.025)$. The significant interaction was explained with results of analyses of variance which showed that the factor, Percentage of Shock, was significant on Trial Block $7,(F=4.00$, $\mathrm{df}=2 / 33, \mathrm{p}<.05)$ but not on Trial Block $12(\mathrm{~F}<1)$ 。

\section{Discussion}

Since Jones' results may be attributable to the starting speed measure, the discrepancy between his acquisition data and those of this study will be discussed in terms of the conditions of escape training in the start boxes of these two studies. Briefly, Jones dropped $S$ into the start box with the shock or non-shock condition already present on the grids. On shock trials, this procedure may have elicited behavior incompatible with escape (e.g. Sheffield \& Temmer (1950) reported the recurrence of "freezing" behavior under similar starting conditions). Due to the frequency of shock occurrence, the depressant effects of these incompatible responses may have been greater for the continuous-shock group than for the intermittent-shock group. In the present study, the 10 sec. interim $S$ waited in the start box before shock onset may have decreased the probability of incompatible responses and may have provided for the occurrence of a postural response (e.g. a "ready" posture), which facilitated escape-from-shock behavior. Thus, due to the greater frequency of shock, the continuous-shock group should perform better than the intermittent group.

\section{References}

Anderson, N. H. Comparison of different populations: Resistance to extinction and transfer. Psychol. Rev., 1963, 70, 162-179. Jones, M. B. An experimental study of extinction. Psychol. Monogr. 1953, 67, Whole No. 369.

Melvin, K. B. Escape learning and "vicious circle" behavior under partial and continuous reinforcement. Unpublished doctoral dissertation, University of Florida, 1963.

Sheffield, F. D., \& Temmer, H. W. Relative resistance to extinction of escape training and avoidance training. J. exp. Psychol., 1950, 40, 287-298.

\section{Notes}

1. Paper delivered at the annual meeting of the Texas Psychological Association, December, 1965.

2. This research was supported by Grant No. 20-97-152 from the Research Institute of Southern Methodist University. 